\title{
Stem cells in articular cartilage regeneration
}

\author{
Giuseppe Filardo ${ }^{1}$, Francesco Perdisa ${ }^{1}$, Alice Roffi ${ }^{*}$, Maurilio Marcacci ${ }^{1,2}$ and Elizaveta Kon ${ }^{1,2}$
}

\begin{abstract}
Background: Mesenchymal stem cells (MSCs) have emerged as a promising option to treat articular chondral defects and early OA stages. However, their potential and limitations for clinical use remain controversial. Thus, the aim of this systematic review was to examine MSCs treatment strategies in order to summarize the current clinical evidence for the treatment of cartilage lesions and OA.

Methods: A systematic review of the literature was performed on the PubMed database using the following string: "cartilage treatment" AND "mesenchymal stem cells". The filters included publications on the clinical use of MSCs for cartilage defects and OA in English language up to 2015.

Results: Our search identified 1639 papers: 60 were included in the analysis, with an increasing number of studies published on this topic over time. Seven were randomized, 13 comparative, 31 case series, and 9 case reports; 26 studies reported the results after injective administration, whereas 33 used surgical implantation. One study compared the 2 different modalities. With regard to the cell source, 20 studies concerned BMSCs, 17 ADSCs, 16 BMC, 5 PBSCs, 1 SDSCs, and 1 compared BMC vs PBSCs.

Conclusions: The available studies allow to draw some indications. First, no major adverse events related to the treatment or to the cell harvest have been reported. Second, a clinical benefit of using MSCs therapies has been reported in most of the studies, regardless of cell-source, indication or administration method. Third, young age, lower BMI, smaller lesion size for focal lesions and earlier stages of OA joints, have been shown to correlate with better outcomes, even though the available data strength doesn't allow to define clear cutoff values.
\end{abstract}

Keywords: MSCs, Mesenchymal stem cells, Osteoarthritis, Cartilage, Osteochondral

\section{Background}

Articular cartilage lesions are a debilitating disease, often resulting in fibrillation and subsequent degradation of the surrounding articular surface, possibly involving the subchondral bone as well, thus favoring the development of osteoarthritis (OA). OA affects up to $15 \%$ of the adult population and represents the second greatest cause of disability worldwide [1], with a massive impact on society both in terms of quality of life for the individuals and high costs for the healthcare system [2]. Several approaches have been proposed for the management of cartilage degeneration, ranging from pharmacological to surgical

\footnotetext{
*Correspondence: a.roffi@biomec.ior.it

${ }^{2}$ Nanobiotechnology Laboratory, Rizzoli Orthopaedic Institute, Via di Barbiano 1/10, 40136 Bologna, Italy

Full list of author information is available at the end of the article
}

options, aimed at reducing symptoms and restoring a satisfactory knee function [3, 4]. However, none of them has clearly shown the potential of restoring chondral surface and physiological joint homeostasis in order to prevent OA, which in the final stage often requires prosthetic replacement.

Among the solutions proposed to delay the need for metal resurfacing of the damaged articular surface, mesenchymal stem cells (MSCs) have recently emerged as a promising option to treat articular defects and early OA stages [5]. MSCs are multipotent progenitor cells that can differentiate into selected lineages including chondrocytes, with capability of self-renewal, high plasticity, and immunosuppressive and anti-inflammatory action [6, 7]. Moreover, Caplan and colleagues [8] recently underlined that these cells, derived from perivascular 
cells called "pericytes", have a key role in the response to tissue injuries not just by differentiating themselves, but also by inducing repair/regeneration processes at the injury site through the secretion of several bioactive molecules [9]. In light of these properties, MSCs represent an excellent candidate for cell therapies and their healing potential has been explored also in terms of cartilage tissue regeneration and OA processes modulation [6]. The first investigations involved MSCs derived from bone marrow, which have been applied either as a cell suspension after being expanded by culture (BMSCs), or used as a simple bone marrow concentrate (BMC), thanks to their relative abundance [6]. Despite an extensive preclinical research and promising clinical results, some drawbacks related to the cell harvest and culture led to the development of different alternative options, with stem cells derived from adipose tissue (ADSCs), synovial tissue (SDSCs), and peripheral blood (PBSCs) $[10,11]$. Besides these sources already explored and reported in the clinical use, cells derived from fetal tissues are being currently investigated at preclinical level [12]. Although numerous advancements have been made, the understanding of MSCs mechanism of action as well as their potential and limitations for the clinical use remain controversial. Many questions are still open on the identification of patients who might benefit more from this kind of treatment, as well as the most suitable protocol of administration (no. of cells, concentrated or culture-expanded, best harvest source, etc.).

Based on these premises, the aim of this systematic review was to examine the literature on MSCs treatment strategies in the clinical setting, in order to summarize the current evidence on their potential for the treatment of cartilage lesions and OA.

\section{Materials and methods}

A systematic review of the literature was performed on the PubMed database by two independent reviewers using the following string: "cartilage treatment" AND "mesenchymal stem cells". The filters included publications on the use of MSCs for cartilage defects and OA in the clinical field and in English language, published from 2000 to the end of 2015. Articles were first screened by title and abstract. Subsequently, the full texts of the resulting articles were screened and those not reporting clinical results of MSCs for cartilage and OA treatment were excluded. The reference lists of the selected articles were also screened to obtain further studies for this review.

\section{Results}

Our search identified 1639 papers after the screening process, 60 were included in the analysis (Fig. 1), which showed an increasing number of studies published on this topic over time (Fig. 2). Among the 60 selected studies, 7 were randomized, 13 comparative, 31 case

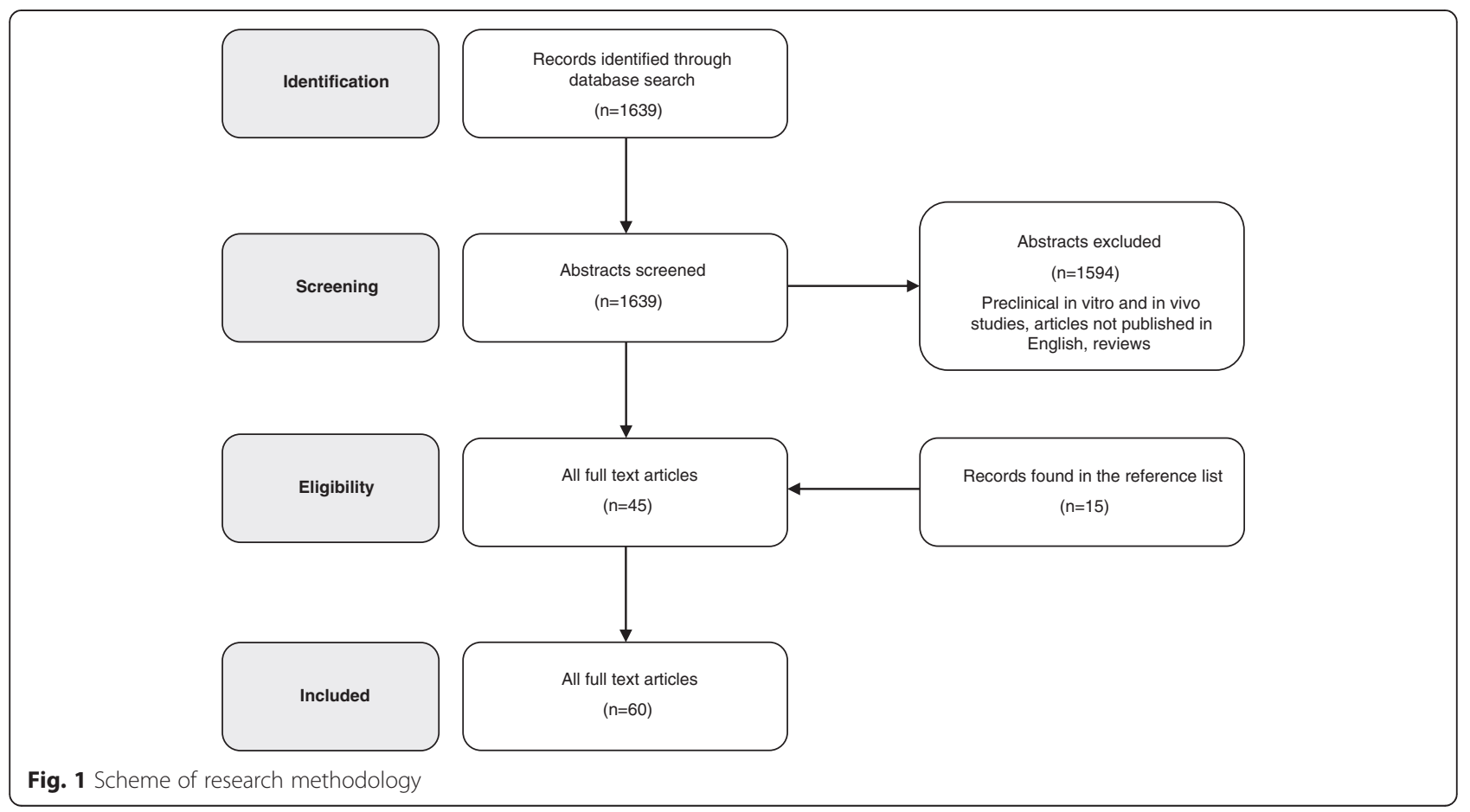




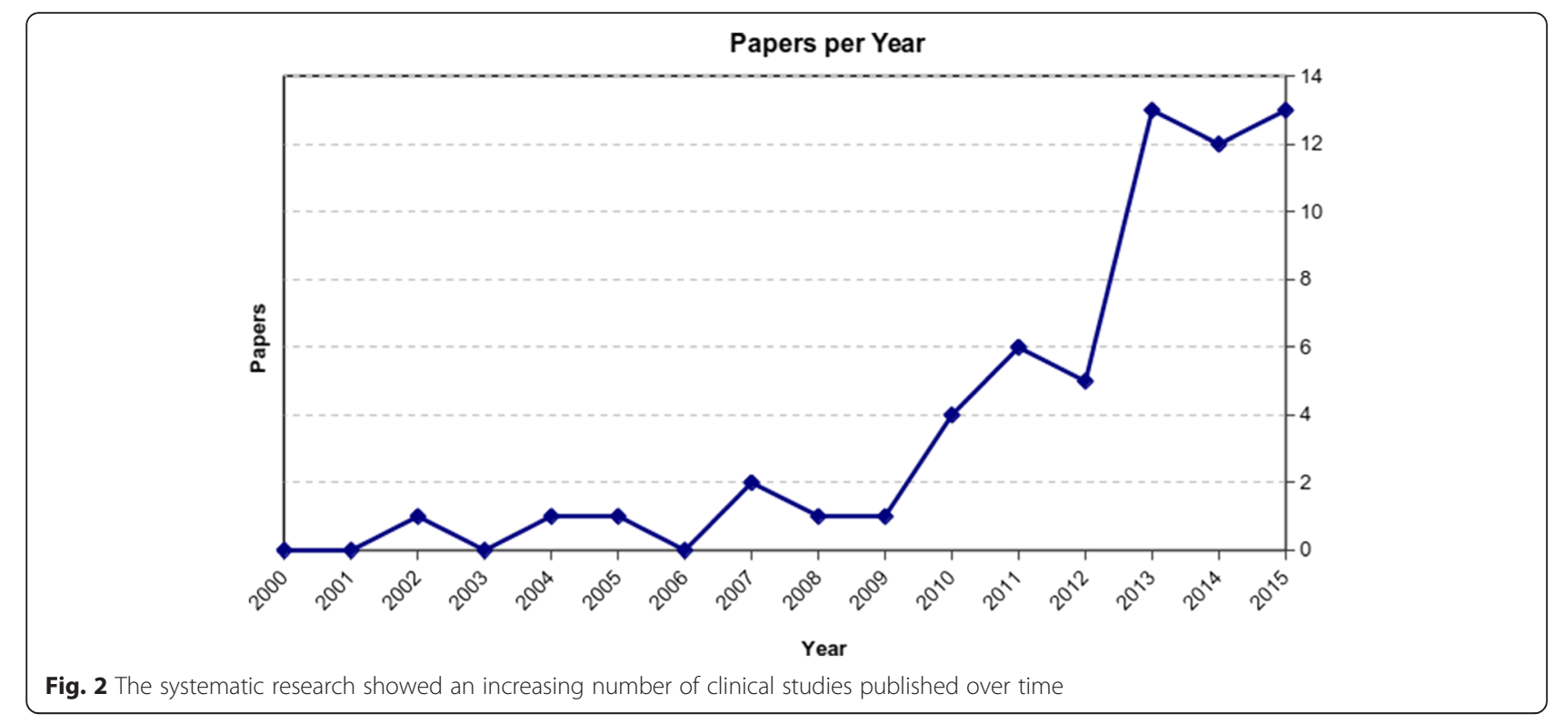

series, and 9 case reports; 26 studies reported the results after injective administration, whereas 33 used surgical implantation. One study compared the two different modalities. With regard to the cell source, 20 studies concerned BMSCs, 17 ADSCs, 16 BMC, 5 PBSCs, 1 SDSCs, and 1 compared BMC versus PBSCs. While all the included studies are summarized in detail in Table 1 according to cell source and treatment strategy, the most relevant findings will be discussed in the following paragraphs.

\section{BMSCs}

An increasing number of papers have been focused on this cell source in the past few years, both as BMSCs and BMC. Cultured BMSCs and BMC differ for composition, since adult bone marrow contains heterogeneous blood cells at various differentiation stages [13]. Thus, the harvest includes plasma, red blood cells, platelets, and nucleated cells, a small fraction of which contains adult MSCs that can be isolated through culture expansion [14]. However, even if not expanded, the heterogeneity of cell progenitor types in BMC might positively influence tissue regeneration [15]. Moreover, cell culture not only offers a higher number of cells but also presents high costs and some regulatory problems, since these products might be considered as pharmacological treatments by regulatory agencies. Thus, one-step techniques using BMC for the delivery of autologous cells in a single time are gaining increasing interest in the clinical setting. Besides these considerations, positive findings are leading the research towards the use of both cellbased strategies.

\section{Cultured BMSCs: injective treatment}

In 2008, Centeno and colleagues [16] first reported the promising clinical and MRI improvements at early follow-up after single intra-articular (i.a.) injection of autologous cultured BMSCs in a patient with knee degenerative cartilage disease, and similar findings at short term were later shown also by the groups of Davatchi [17], Emadedin [18], and Sol Rich [19]. Orozco et al. confirmed a rapid and progressive clinical improvement of knee OA in the first 12 months [20], which was maintained at 24-month follow-up, together with improved cartilage quality at MRI [21]. Finally, Davatchi et al. [22] updated their report, showing gradual mid-term deterioration of the outcomes in advanced OA.

Among comparative studies, Lee et al. [23] tested two administration strategies for focal knee cartilage defects and found no differences either by using BMSCs implantation under periosteum flap or microfractures (MFX) plus BMSCs i.a. injection, thus endorsing the less invasive approach.

Three randomized controlled trials (RCTs) have also been published. Wong et al. [24] treated knee unicompartmental OA with varus malalignment by combined high tibial osteotomy (HTO) and MFX. Patients randomly received post-operative i.a. injection of BMSCshyaluronic acid (HA) or $\mathrm{HA}$ alone as control. Both groups improved their scores, but BMSCs produced better clinical and MRI outcomes. Vangsness et al. [25] administered a single i.a. injection in patients after medial partial meniscectomy. Patients were randomized in two treatment groups (low- or high-dose allogeneic cultured BMSCs with HA) and a control group (HA-only). Both treatment groups showed improved clinical scores versus control, and MRI showed signs of meniscal volume 
Table 1 Details of the 60 clinical trials identified by the systematic review focusing on MSCs use for the treatment of cartilage pathology

\begin{tabular}{|c|c|c|c|c|c|c|c|c|}
\hline MSCs & Publication & Study type & Treatment & Additional information & Pathology & $N$ patients & Follow-up & Results \\
\hline \multirow[t]{12}{*}{$\begin{array}{l}\text { Cultured } \\
\text { BMSCs }\end{array}$} & $\begin{array}{l}\text { Davatchi [22] } 2015 \\
\text { Int Journal of Rheum } \\
\text { Disease }\end{array}$ & Case series & IA injection & Previous study update & Knee OA & 3 & 60 months & $\begin{array}{l}\text { Still significant improvement at } \\
5 \text { years, but gradual worsening } \\
\text { after 6-month follow-up }\end{array}$ \\
\hline & $\begin{array}{l}\text { Vega [26] } 2015 \\
\text { Transplantation }\end{array}$ & $\mathrm{RCT}$ & IA injection & Allogeneic BMSCs & Knee OA & $\begin{array}{l}15 \text { BMSCs } \\
15 \mathrm{HA}\end{array}$ & 12 months & $\begin{array}{l}\text { Significant better functional and } \\
\text { cartilage quality improvements in } \\
\text { MSCs group vs. control }\end{array}$ \\
\hline & $\begin{array}{l}\text { Sol Rich [18] } 2015 \\
\text { J Stem Cell Res Ther }\end{array}$ & Case series & IA injection & & Knee OA & 12 & 24 months & $\begin{array}{l}\text { Excellent clinical and quantitative } \\
\text { MRI outcome measures at } 2 \text { years }\end{array}$ \\
\hline & $\begin{array}{l}\text { Vangsness [25] } 2014 \\
\text { JBJS Am }\end{array}$ & RCT & IA injection & $\begin{array}{l}\text { Allogeneic BMSCs } \\
\text { After medial } \\
\text { meniscectomy }\end{array}$ & Knee OA & $\begin{array}{l}18 \text { low-dose MSCs + } \\
\text { HA } \\
18 \text { high-dose MSCs + } \\
\text { HA } \\
19 \text { HA }\end{array}$ & 24 months & $\begin{array}{l}\text { Knee pain improvement and } \\
\text { evidence of meniscus } \\
\text { regeneration at MRI for both } \\
\text { doses vs. control }\end{array}$ \\
\hline & $\begin{array}{l}\text { Orozco [21] } 2014 \\
\text { Transplantation }\end{array}$ & Case series & IA injection & Previous study update & Knee OA & 12 & 24 months & $\begin{array}{l}\text { Pain improvement at } 12 \text { months } \\
\text { maintained at } 24 \text { months. } \\
\text { The quality of cartilage further } \\
\text { improved at MRI at } 24 \text { months }\end{array}$ \\
\hline & $\begin{array}{l}\text { Wong [24] } 2013 \\
\text { Arthroscopy }\end{array}$ & RCT & IA injection & $\begin{array}{l}\text { Comb HTO + MFX and } \\
\text { post-op injection }\end{array}$ & Knee OA & $\begin{array}{l}28 \mathrm{BMSCS}+\mathrm{HA} \\
28 \mathrm{HA}\end{array}$ & 24 months & $\begin{array}{l}\text { BMSCs i.a. injection produced } \\
\text { superior clinical and MRI } \\
\text { outcomes at } 24 \text { months }\end{array}$ \\
\hline & $\begin{array}{l}\text { Ricther [35] } 2013 \\
\text { Foot \& Ankle }\end{array}$ & Case series & Surgical delivery & $\begin{array}{l}\text { MAST } \\
\text { Collagen membrane }\end{array}$ & $\begin{array}{l}\text { Ankle chondral } \\
\text { defects }\end{array}$ & 25 & 24 months & $\begin{array}{l}\text { No adverse events. } \\
\text { Clinical scores improvement } \\
\text { Positive findings at histology }\end{array}$ \\
\hline & $\begin{array}{l}\text { Orozco [22] } 2013 \\
\text { Transplantation }\end{array}$ & Case series & IA injection & & Knee OA & 12 & 12 months & $\begin{array}{l}\text { No safety issues. Rapid and } \\
\text { progressive clinical improvement } \\
\text { at } 12 \text { months } \\
11 / 12 \text { patients increased cartilage } \\
\text { quality at MRI }\end{array}$ \\
\hline & $\begin{array}{l}\text { Lee [23] } 2012 \\
\text { Ann Accad Med } \\
\text { Singapore }\end{array}$ & Comparative & IA injection & & $\begin{array}{l}\text { Knee cartilage } \\
\text { defects }\end{array}$ & $\begin{array}{l}35 \mathrm{MFX}+\mathrm{BMSCs}+\mathrm{HA} \\
35 \mathrm{BMSC}+\text { periosteal } \\
\text { patch }\end{array}$ & 24 months & $\begin{array}{l}\text { MFX + BMSCs + HA had } \\
\text { comparable results vs. BMSCs + } \\
\text { periosteal patch, but lower } \\
\text { invasivity }\end{array}$ \\
\hline & $\begin{array}{l}\text { Emadedin [19] } 2012 \\
\text { Arch Iran Med }\end{array}$ & Case series & IA injection & & Knee OA & 6 & 12 months & $\begin{array}{l}\text { No local or systemic adverse } \\
\text { events. } \\
\text { Decreased pain, improved } \\
\text { function and walking distance } \\
3 / 6 \text { increased cartilage thickness } \\
\text { at MRI }\end{array}$ \\
\hline & $\begin{array}{l}\text { Kasemkijwattana [29] } \\
2011 \\
\text { J Med Assoc Thai }\end{array}$ & Case report & Surgical delivery & $\begin{array}{l}\text { MAST } \\
\text { Collagen membrane }\end{array}$ & $\begin{array}{l}\text { Knee cartilage } \\
\text { defects }\end{array}$ & 2 & 31 months & $\begin{array}{l}\text { Significant clinical improvement } \\
\text { Good filling, tissue stiffness, and } \\
\text { integration at 2nd look }\end{array}$ \\
\hline & $\begin{array}{l}\text { Davatchi [17] } 2011 \\
\text { Int J Rheum Dis }\end{array}$ & Case series & IA injection & & Knee OA & 4 & 12 months & $\begin{array}{l}\text { Encouraging clinical results no X- } \\
\text { Rays improvement }\end{array}$ \\
\hline
\end{tabular}


Table 1 Details of the 60 clinical trials identified by the systematic review focusing on MSCs use for the treatment of cartilage pathology (Continued)

\begin{tabular}{|c|c|c|c|c|c|c|c|c|}
\hline & $\begin{array}{l}\text { Haleem [28] } 2010 \\
\text { Cartilage }\end{array}$ & Case series & Surgical delivery & $\begin{array}{l}\text { MAST } \\
\text { PRF as scaffold }\end{array}$ & $\begin{array}{l}\text { Knee cartilage } \\
\text { defects }\end{array}$ & 5 & 12 months & $\begin{array}{l}5 / 5 \text { symptoms improvement } \\
\text { Complete defect filling and } \\
\text { surface congruity with native } \\
\text { cartilage in } 3 / 5 \text { at MRI }\end{array}$ \\
\hline & $\begin{array}{l}\text { Nejadnik [34] } 2010 \\
\text { AJSM }\end{array}$ & Comparative & Surgical delivery & BMSCs + periosteal flap & $\begin{array}{l}\text { Knee cartilage } \\
\text { defects }\end{array}$ & $\begin{array}{l}36 \mathrm{ACl} \\
36 \mathrm{BMSCs}+\text { periosteal } \\
\text { flap }\end{array}$ & 24 months & $\begin{array}{l}\text { Comparable improvement in } \\
\text { quality of life, health, and sport } \\
\text { activity. M better than F, older } \\
\text { than } 45 \text { years lower improvement } \\
\text { only in ACl group. }\end{array}$ \\
\hline & $\begin{array}{l}\text { Centeno [16] } 2008 \\
\text { Pain Physician }\end{array}$ & Case report & IA injection & & $\begin{array}{l}\text { Knee cartilage } \\
\text { defects }\end{array}$ & $\begin{array}{l}1 \text { IA BMSCs + } 2 \text { weekly } \\
\text { platelet lysate IA } \\
\text { injections }\end{array}$ & 24 months & $\begin{array}{l}\text { Improvement of range of motion } \\
\text { and pain scores. Significant } \\
\text { cartilage and meniscus growth at } \\
\text { MRI }\end{array}$ \\
\hline & $\begin{array}{l}\text { Kuroda [30] } 2007 \\
\text { Osteoarthritis \& } \\
\text { Cartilage }\end{array}$ & Case report & Surgical delivery & $\begin{array}{l}\text { BMSCs + collagen gel } \\
+ \text { periosteum }\end{array}$ & $\begin{array}{l}\text { Knee cartilage } \\
\text { defects }\end{array}$ & 1 & 12 months & $\begin{array}{l}\text { Hyaline-like tissue regeneration, } \\
\text { improvement in clinical } \\
\text { symptoms and return to previous } \\
\text { activity level }\end{array}$ \\
\hline & $\begin{array}{l}\text { Wakitani [31] } 2007 \\
\text { J Tissue Eng Regen } \\
\text { Med }\end{array}$ & Case report & Surgical delivery & $\begin{array}{l}\text { BMSCs + collagen gel } \\
+ \text { periosteum or } \\
\text { synovium }\end{array}$ & $\begin{array}{l}\text { Knee cartilage } \\
\text { defect patella }\end{array}$ & 3 & 17-27 months & $\begin{array}{l}\text { Improvement in clinical } \\
\text { symptoms maintained over time. } \\
\text { Fibrocartilaginous tissue at } \\
\text { histology }\end{array}$ \\
\hline & $\begin{array}{l}\text { Adachi [27] } 2005 \\
\text { J Rheumatol }\end{array}$ & Case report & Surgical delivery & $\begin{array}{l}\text { MAST } \\
\text { Hydroxyapatite ceramic }\end{array}$ & $\begin{array}{l}\text { Knee } \\
\text { osteochondral } \\
\text { defect }\end{array}$ & 1 & & $\begin{array}{l}\text { Cartilage-like and bone tissue } \\
\text { regeneration at } 2 \text { nd look } \\
\text { arthroscopy }\end{array}$ \\
\hline & $\begin{array}{l}\text { Wakitani [32] } 2004 \\
\text { Cell Transplant }\end{array}$ & Case report & Surgical delivery & $\begin{array}{l}\text { BMSCs + collagen gel } \\
+ \text { periosteum }\end{array}$ & $\begin{array}{l}\text { Knee cartilage } \\
\text { defect } \\
\text { Patella }\end{array}$ & 2 & 5 years & $\begin{array}{l}\text { Short-term clinical improvement, } \\
\text { then stable at } 24 \text { months } \\
\text { fibrocartilage defect filling }\end{array}$ \\
\hline & $\begin{array}{l}\text { Wakitani [33] } 2002 \\
\text { Osteoarthritis \& } \\
\text { Cartilage }\end{array}$ & Comparative & Surgical delivery & $\begin{array}{l}\text { Collagen gel sheet + } \\
\text { periosteum }\end{array}$ & Knee OA & $\begin{array}{l}12 \text { BMSCs + HTO } \\
12 \text { cell-free control + } \\
\text { HTO }\end{array}$ & 16 months & $\begin{array}{l}\text { Comparable clinical outcomes, } \\
\text { but better arthroscopic and } \\
\text { histological score in cell- } \\
\text { transplanted group }\end{array}$ \\
\hline \multirow[t]{2}{*}{ BM Concentrate } & $\begin{array}{l}\text { Gobbi [47] } 2015 \\
\text { Cartilage }\end{array}$ & Comparative & Surgical delivery & $\begin{array}{l}\text { MAST } \\
\text { HA matrix }\end{array}$ & $\begin{array}{l}\text { Knee cartilage } \\
\text { defects } \\
\text { patellofemoral }\end{array}$ & $\begin{array}{l}19 \mathrm{MACT} \\
18 \mathrm{BMC}\end{array}$ & 3 years & $\begin{array}{l}\text { Significant scores improvement in } \\
\text { both groups. } \\
\text { Better IKDC subj for BMC. MACl: } \\
\text { trochlea better than patella; BMC: } \\
\text { site n.s. } \\
\text { Better filling at MRI for BMC }\end{array}$ \\
\hline & $\begin{array}{l}\text { Buda [40] } 2015 \\
\text { Arch Orthop Trauma } \\
\text { Surg }\end{array}$ & Case series & Surgical delivery & $\begin{array}{l}\text { MAST } \\
\text { HA matrix }\end{array}$ & OLTs and ankle OA & 56 & 36 months & $\begin{array}{l}\text { Clinical outcome improvement at } \\
12 \text { months, further increase at } \\
24 \text { months and lowering trend at } \\
36 \text { months } \\
\text { Higher BMl and OA degree had } \\
\text { worse results }\end{array}$ \\
\hline
\end{tabular}


Table 1 Details of the 60 clinical trials identified by the systematic review focusing on MSCs use for the treatment of cartilage pathology (Continued)

\begin{tabular}{|c|c|c|c|c|c|c|c|}
\hline $\begin{array}{l}\text { Buda [39] } 2015 \\
\text { Cartilage }\end{array}$ & Case series & Surgical delivery & $\begin{array}{l}\text { MAST } \\
\text { HA matrix }\end{array}$ & $\begin{array}{l}\text { Ankle osteochondral } \\
\text { lesions (hemophilic } \\
\text { patients) }\end{array}$ & 5 & 24 months & $\begin{array}{l}\text { Clinical improvement at } 2 \text { years. } \\
3 \text { patients back to sports. } \\
\text { Signs of cartilage and bone tissue } \\
\text { regeneration at MRI. } \\
\text { No radiographic joint } \\
\text { degeneration progression }\end{array}$ \\
\hline $\begin{array}{l}\text { Buda R [43] } 2015 \\
\text { Int Orthop }\end{array}$ & Comparative & Surgical delivery & $\begin{array}{l}\text { MAST } \\
\text { HA matrix + PRF }\end{array}$ & OLTs & $\begin{array}{l}40 \mathrm{ACl} \\
40 \mathrm{BMC}\end{array}$ & 48 months & $\begin{array}{l}\mathrm{ACl} \text { and MAST was equally } \\
\text { effective for the treatment of OLT. } \\
\text { MAST preferred for the } 1 \text { step } \\
\text { procedure, and lower costs }\end{array}$ \\
\hline $\begin{array}{l}\text { Gobbi [50] } 2014 \\
\text { AJSM }\end{array}$ & Case series & Surgical delivery & $\begin{array}{l}\text { MAST } \\
\text { Collagen membrane }\end{array}$ & $\begin{array}{l}\text { Knee chondral } \\
\text { defects }\end{array}$ & 25 & 3 years & $\begin{array}{l}\text { Significant scores improvement } \\
\text { Older than } 45 \text { and smaller or } \\
\text { single lesions showed better } \\
\text { outcomes. } \\
\text { Good implant stability and } \\
\text { complete filling at MRI. }\end{array}$ \\
\hline $\begin{array}{l}\text { Cadossi [44] } 2014 \\
\text { Foot Ankle Int }\end{array}$ & $\mathrm{RCT}$ & Surgical delivery & $\begin{array}{l}\text { MAST } \\
\text { HA matrix }\end{array}$ & OLTs & $\begin{array}{l}15 \text { BMDCs + HA + PEMF } \\
15 \text { BMDCs + HA }\end{array}$ & 12 months & $\begin{array}{l}\text { Biophysical stimulation started } \\
\text { soon after surgery aided patient } \\
\text { recovery leading to pain control } \\
\text { and a better clinical outcome } \\
\text { with these improvements lasting } \\
\text { more than } 1 \text { year after surgery }\end{array}$ \\
\hline $\begin{array}{l}\text { Buda [41] } 2014 \\
\text { Joints }\end{array}$ & Case series & Surgical delivery & $\begin{array}{l}\text { MAST } \\
\text { HA/collagen powder } \\
\text { matrix + PRF }\end{array}$ & OLTS & $\begin{array}{l}41 \mathrm{BMAC}+\mathrm{HA}+\mathrm{PRF} \\
23 \mathrm{BMAC}+\text { collagen } \\
\text { powder + PRF }\end{array}$ & 53 months & $\begin{array}{l}\text { Significant clinical improvement, } \\
\text { gradual decrease after } 24+\text { months }\end{array}$ \\
\hline $\begin{array}{l}\text { Skowronski [51] } 2013 \\
\text { Orthop Traumatol } \\
\text { Rehabil }\end{array}$ & Case series & Surgical delivery & $\begin{array}{l}\text { MAST } \\
\text { Collagen membrane }\end{array}$ & $\begin{array}{l}\text { Knee chondral } \\
\text { defects }\end{array}$ & 54 & 5 years & $\begin{array}{l}\text { Improvement in clinical scores in 52/ } \\
54 \text { patients without complications } \\
\text { After } 5 \text { years n.s. deterioration in } 3 \\
\text { patients }\end{array}$ \\
\hline $\begin{array}{l}\text { Giannini [38] } 2013 \\
\text { AJSM }\end{array}$ & Case series & Surgical delivery & $\begin{array}{l}\text { MAST } \\
\text { HA membrane or } \\
\text { collagen powder }+ \\
\text { PRF }\end{array}$ & OLTS & 49 & 24-48 months & $\begin{array}{l}\text { Good clinical results at } \\
24 \text { months, then significant } \\
\text { decrease at } 36 \text { and } 48 \text { months. T2 } \\
\text { mapping similar to native hyaline } \\
\text { cartilage and correlate with the } \\
\text { clinical results }\end{array}$ \\
\hline $\begin{array}{l}\text { Buda [46] } 2013 \\
\text { Muskuloskeletal Surg }\end{array}$ & Case series & Surgical delivery & $\begin{array}{l}\text { MAST } \\
\text { HA matrix }\end{array}$ & OLKs & 30 & 29 months & $\begin{array}{l}\text { Good clinical outcome } \\
\text { osteochondral regeneration at } \\
\text { control MRI and biopsies }\end{array}$ \\
\hline $\begin{array}{l}\text { Gigante [48] } 2012 \\
\text { Arhtroscopy Technique }\end{array}$ & Case report & Surgical delivery & $\begin{array}{l}\text { MAST } \\
\text { Collagen membrane + } \\
\text { MFX }\end{array}$ & $\begin{array}{l}\text { Knee chondral } \\
\text { defects }\end{array}$ & 1 & 24 months & $\begin{array}{l}\text { Pain free at } 6 \text { months, still } \\
\text { asymptomatic at } 24 \text { months } \\
\text { Positive MRI tissue appearance at } \\
12 \text { months }\end{array}$ \\
\hline $\begin{array}{l}\text { Gigante [49] } 2011 \\
\text { Int J Immunopathol } \\
\text { Pharmacol }\end{array}$ & Case series & Surgical delivery & $\begin{array}{l}\text { MAST } \\
\text { collagen membrane }\end{array}$ & $\begin{array}{l}\text { Knee chondral } \\
\text { defects }\end{array}$ & 5 & 12 months & $\begin{array}{l}\text { Patients asymptomatic } \\
\text { Nearly normal arthroscopic } \\
\text { appearance and satisfactory repair } \\
\text { tissue at } 12 \text { months }\end{array}$ \\
\hline
\end{tabular}


Table 1 Details of the 60 clinical trials identified by the systematic review focusing on MSCs use for the treatment of cartilage pathology (Continued)

\begin{tabular}{|c|c|c|c|c|c|c|c|c|}
\hline & $\begin{array}{l}\text { Giannini [42] } 2010 \\
\text { Injury }\end{array}$ & Comparative & Surgical delivery & $\begin{array}{l}\text { MAST } \\
\text { HA matrix + PRF }\end{array}$ & OLTS & $\begin{array}{l}10 \mathrm{ACl} \text { open } \\
46 \text { arthroscopic MACT } \\
25 \text { arthroscopic MAST }\end{array}$ & 36 months & $\begin{array}{l}\text { Similar clinical improvement } \\
\text { among groups. } \\
\text { Good restoration of the } \\
\text { cartilaginous layer with hyaline- } \\
\text { like characteristics at MRI and } \\
\text { histology }\end{array}$ \\
\hline & $\begin{array}{l}\text { Varma [36] } 2010 \\
J \text { Indian Med Assoc }\end{array}$ & Comparative & IA injection & $\begin{array}{l}\text { Augmentation to } \\
\text { debridement }\end{array}$ & Knee OA & $\begin{array}{l}25 \text { Debridement }+ \text { BMC } \\
25 \text { Debridement alone }\end{array}$ & 6 months & $\begin{array}{l}\text { BMC: higher improvement in } \\
\text { symptoms, function, and quality } \\
\text { of life }\end{array}$ \\
\hline & $\begin{array}{l}\text { Buda [45] } 2010 \\
\text { JBJS Am }\end{array}$ & Case series & Surgical delivery & $\begin{array}{l}\text { MAST } \\
\text { HA matrix + PRF }\end{array}$ & OLKs & 20 & 24 months & $\begin{array}{l}\text { Significant clinical improvement } \\
\text { at } 12 \text { and } 24 \text { months. Associated } \\
\text { procedures delayed recovery. } \\
\text { Satisfactory MRI findings in } 80 \% \\
\text { of patients }\end{array}$ \\
\hline & $\begin{array}{l}\text { Giannini [37] } 2009 \\
\text { Clin Orthop Rel Res }\end{array}$ & Case series & Surgical delivery & $\begin{array}{l}\text { MAST } \\
\text { HA matrix or collagen } \\
\text { powder + PRF }\end{array}$ & OLTS & 48 & 24 months & $\begin{array}{l}\text { Clinical improvement } \\
\text { Regenerated tissue in various } \\
\text { degree of remodeling, none had } \\
\text { complete hyaline-like features at } \\
\text { histology }\end{array}$ \\
\hline \multirow[t]{5}{*}{ PBSCs } & $\begin{array}{l}\text { Fu [55] } 2014 \\
\text { Knee }\end{array}$ & Case report & Surgical delivery & $\begin{array}{l}\text { PBSCs }+ \text { autologous } \\
\text { Periosteal flap }+ \\
\text { patellofemoral } \\
\text { realignment }\end{array}$ & $\begin{array}{l}\text { Knee chondral } \\
\text { defects }\end{array}$ & 1 & 7.5 years & $\begin{array}{l}\text { Patient returned to competitive } \\
\text { kickboxing } \\
\text { Smooth surface } 8 \text { months after } \\
\text { surgery } \\
\text { Significant clinical and MRI } \\
\text { improvements }\end{array}$ \\
\hline & $\begin{array}{l}\text { Turajane [53] T } 2013 \\
\text { J Med Assoc Thai }\end{array}$ & Case series & IA injection & $\begin{array}{l}\text { PBSCs + GFs addition/ } \\
\text { preservation + HA + } \\
\text { microdrilling }\end{array}$ & Knee OA & 5 & 6 months & $\begin{array}{l}\text { Improvement in all clinical scores } \\
\text { without adverse events }\end{array}$ \\
\hline & $\begin{array}{l}\text { Saw [54] } 2013 \\
\text { Arthroscopy }\end{array}$ & $\mathrm{RCT}$ & IA injection & $\begin{array}{l}\text { Subchondral drilling } \\
\text { PBSCs + HA vs. HA } \\
5 \text { IA injections post-op } \\
3 \text { more IA injections } \\
\text { after } 6 \text { months }\end{array}$ & $\begin{array}{l}\text { Knee chondral } \\
\text { defects }\end{array}$ & $\begin{array}{l}25 \text { drilling + (PBSCs + } \\
\text { HA) } \\
25 \text { drilling + HA }\end{array}$ & 2 years & $\begin{array}{l}\text { Comparable significant clinical } \\
\text { improvement for both groups } \\
\text { PBSCs + HA had both MRI and } \\
\text { histology superior vs. control } \\
\text { group }\end{array}$ \\
\hline & $\begin{array}{l}\text { Skowronski [56] } 2012 \\
\text { Orthop Traumatol } \\
\text { Rehabil }\end{array}$ & Case series & Surgical delivery & $\begin{array}{l}\text { PBSCs covered by } \\
\text { collagen membrane }\end{array}$ & $\begin{array}{l}\text { Knee chondral } \\
\text { defects }\end{array}$ & 52 & 6 years & $\begin{array}{l}\text { No adverse events } \\
\text { Improvement in all clinical scores } \\
\text { at } 12 \text { months. Poor outcomes in } \\
2 \text { patients at } 12 \text { months } \\
\text { At } 72 \text { months minor deterioration } \\
\text { in } 2 \text { more patients }\end{array}$ \\
\hline & $\begin{array}{l}\text { Saw [52] } 2011 \\
\text { Arthroscopy }\end{array}$ & Case series & IA injection & $\begin{array}{l}\text { Subchondral drilling + } \\
5 \text { weekly IA injections }\end{array}$ & $\begin{array}{l}\text { Knee chondral } \\
\text { defects }\end{array}$ & 5 & $\begin{array}{l}10- \\
26 \text { months }\end{array}$ & $\begin{array}{l}\text { No adverse events hyaline } \\
\text { cartilage regeneration at histology }\end{array}$ \\
\hline BMC vs. PBSCs & $\begin{array}{l}\text { Skowronski [77] } 2013 \\
\text { Orthop Traumatol } \\
\text { Rehabil }\end{array}$ & Comparative & Surgical delivery & $\begin{array}{l}\text { PBSCs vs. BMC covered } \\
\text { by collagen membrane }\end{array}$ & OLKs & $\begin{array}{l}21 \mathrm{BMC} \\
25 \mathrm{PBSCs}\end{array}$ & 5 years & $\begin{array}{l}\text { Superior results in PBSCs group: } \\
\text { good cartilaginous surface and } \\
\text { integration. Slight clinical scores } \\
\text { decrease in both groups at } \\
60 \text { months }\end{array}$ \\
\hline
\end{tabular}


Table 1 Details of the 60 clinical trials identified by the systematic review focusing on MSCs use for the treatment of cartilage pathology (Continued)

\begin{tabular}{|c|c|c|c|c|c|c|c|c|}
\hline SDSCs & $\begin{array}{l}\text { Sekiya [76] } 2015 \\
\text { Clin Orthop Relat Res }\end{array}$ & Case series & Surgical delivery & $\begin{array}{l}\text { Cultured cells } \\
\text { Scaffold free }\end{array}$ & $\begin{array}{l}\text { Knee chondral } \\
\text { defects }\end{array}$ & 10 & 48 months & $\begin{array}{l}\text { Significant clinical improvement } \\
\text { Positive findings at MRI, and } \\
\text { hyaline like in } 3 / 4 \text { at histology }\end{array}$ \\
\hline \multirow[t]{7}{*}{ ADSCs } & $\begin{array}{l}\text { Kim [71] } 2015 \\
\text { AJSM }\end{array}$ & Comparative & $\begin{array}{l}\text { Surgical delivery } \\
\text { vs. IA injection }\end{array}$ & $\begin{array}{l}\text { Subcutaneous fat } \\
\text { SVF on FG scaffold vs. } \\
\text { PRP-SVF injection }\end{array}$ & $\begin{array}{l}\text { Isolated focal } \\
\text { defects in knee OA }\end{array}$ & $\begin{array}{l}20 \text { SVF-FG } \\
20 \text { SVF-PRP }\end{array}$ & 28.6 months & $\begin{array}{l}\text { Significant improvement in both } \\
\text { groups. Better clinical results at } \\
\text { final f-up and } 2 \text { nd look } \\
\text { appearance at } 12 \text { months for SVF- } \\
\text { FG. No. of cells correlated with } \\
\text { outcomes only for injective group }\end{array}$ \\
\hline & $\begin{array}{l}\text { Kim [72] } 2015 \\
\text { Osteoarthritis Cartilage }\end{array}$ & Case series & Surgical delivery & $\begin{array}{l}\text { Subcutaneous fat } \\
\text { SVF + FG scaffold }\end{array}$ & $\begin{array}{l}\text { Isolated focal } \\
\text { defects in OA knee }\end{array}$ & 20 & 27.9 months & $\begin{array}{l}\text { Significant clinical and MRI scores } \\
\text { improvement } \\
\text { MRI correlates with clinical } \\
\text { outcomes }\end{array}$ \\
\hline & $\begin{array}{l}\text { Michalek [67] } 2015 \\
\text { Cell Transplant }\end{array}$ & Case series & IA injection & $\begin{array}{l}\text { Subcutaneous fat } \\
\text { SVF }\end{array}$ & OA (various joints) & 1114 & 17.2 months & $\begin{array}{l}\text { No adverse effects, safe, cost- } \\
\text { effective } \\
\text { Clinical improvement at } \\
3-12 \text { months. } \\
\text { Follow-up at } 12 \text { months: } 63 \% \\
\text { patients had } \geq 75 \% \text { score } \\
\text { improvement } \\
91 \% \text { patients had } \geq 50 \% \text { score } \\
\text { improvement } \\
\text { Slower healing for obese and } \\
\text { worse OA }\end{array}$ \\
\hline & $\begin{array}{l}\text { Koh [74] } 2015 \\
\text { Arthroscopy }\end{array}$ & $\mathrm{RCT}$ & Surgical delivery & $\begin{array}{l}\text { Subcutaneous fat } \\
\text { MFX }+ \text { FG + SVF vs. } \\
\text { MFX }\end{array}$ & $\begin{array}{l}\text { Knee chondral } \\
\text { defects }\end{array}$ & $\begin{array}{l}40 \mathrm{MFX}+\text { SVF-FG } \\
40 \mathrm{MFX}\end{array}$ & 27.4 months & $\begin{array}{l}\text { KOOS pain and symptoms better } \\
\text { for SVF vs. control } \\
\text { 2nd look: complete coverage } 65 \\
\text { vs. } 45 \% \\
\text { SVF better MRI scores }\end{array}$ \\
\hline & $\begin{array}{l}\text { Kim [73] } 2015 \\
\text { AJSM }\end{array}$ & Case series & Surgical delivery & $\begin{array}{l}\text { Subcutaneous fat } \\
\text { SVF + FG }\end{array}$ & $\begin{array}{l}\text { Isolated Focal } \\
\text { defects in OA knee }\end{array}$ & 49 & 26.7 months & $\begin{array}{l}74.5 \% \text { good/excellent results } \\
\text { Patient age }>60 \text { years or lesion } \\
\text { size }>6.0 \mathrm{~cm}^{2} \text { are predictors of } \\
\text { clinical failure }\end{array}$ \\
\hline & $\begin{array}{l}\text { Jo [59] } 2014 \\
\text { Stem cell }\end{array}$ & Case series & IA injection & $\begin{array}{l}\text { Cultured subcutaneous } \\
\text { Phase I: low dose } \\
\left(1.0 \times 10^{7}\right) \text { vs. mid-dose } \\
\left(5.0 \times 10^{7}\right) \text { vs. high } \\
\text { dose }\left(1.0 \times 10^{8}\right) \\
\text { Phase II: } 18 \text { patients re- } \\
\text { ceived only high dose }\end{array}$ & Knee OA & $\begin{array}{l}\text { Phase I: } 9 \\
\text { Phase II: } 18\end{array}$ & 6 months & $\begin{array}{l}\text { High-dose was more effective for } \\
\text { knee function improvement } \\
\text { MRl: decreased defect size and } \\
\text { improved cartilage volume } \\
\text { No adverse events related to cell } \\
\text { dose }\end{array}$ \\
\hline & $\begin{array}{l}\text { Kim [69] } 2014 \\
\text { AJSM }\end{array}$ & Comparative & IA injection & $\begin{array}{l}\text { Subcutaneous fat } \\
\text { SVF + marrow } \\
\text { stimulation vs. marrow } \\
\text { stimulation }\end{array}$ & OLTs & $\begin{array}{l}24 \text { marrow stim }+ \text { SVF } \\
26 \text { marrow stimulation }\end{array}$ & 21.9 months & $\begin{array}{l}\text { All clinical and MRI scores in SVF } \\
\text { group improved significantly with } \\
\text { respect to marrow stimulation } \\
\text { alone SVF gave better outcomes } \\
\text { for patients older than } 46.1 \text { years, } \\
\text { lesion size }>152.2 \mathrm{~mm}^{2} \text {, or in } \\
\text { presence of subchondral cysts }\end{array}$ \\
\hline
\end{tabular}


Table 1 Details of the 60 clinical trials identified by the systematic review focusing on MSCs use for the treatment of cartilage pathology (Continued)

\begin{tabular}{|c|c|c|c|c|c|c|c|}
\hline $\begin{array}{l}\text { Kim [71] } 2014 \\
\text { AJSM }\end{array}$ & Comparative & Surgical delivery & $\begin{array}{l}\text { Subcutaneous fat } \\
\text { SVF local adherent vs. } \\
\text { SVF + FG }\end{array}$ & $\begin{array}{l}\text { Isolated focal } \\
\text { defects in OA knee }\end{array}$ & $\begin{array}{l}17 \text { FG } \\
37 \text { scaffold-free }\end{array}$ & 28.6 months & $\begin{array}{l}\text { Both comparable clinical } \\
\text { improvement } \\
\text { 2nd look arthrosocopy at } \\
12.3 \text { months f-up: better ICRS } \\
\text { scores for FG group }\end{array}$ \\
\hline $\begin{array}{l}\text { Bui [62] } 2014 \\
\text { Biomed Res Ther }\end{array}$ & Case series & IA injection & $\begin{array}{l}\text { Subcutaneous fat } \\
\text { SVF + PRP }\end{array}$ & Knee OA & 21 & 8.5 months & $\begin{array}{l}\text { Significant clinical scores } \\
\text { improvement. No side effects. } \\
\text { MRI: increased cartilage thickness }\end{array}$ \\
\hline $\begin{array}{l}\text { Koh [70] } 2014 \\
\text { AJSM }\end{array}$ & Case series & Surgical delivery & $\begin{array}{l}\text { Subcutaneous fat } \\
\text { SVF }\end{array}$ & $\begin{array}{l}\text { Isolated focal } \\
\text { defects in knee OA }\end{array}$ & 35 & 26.5 months & $\begin{array}{l}\text { Clinical improvement } \\
76 \% \text { abnormal repair tissue at } \\
2 \text { nd look arthroscopy } \\
\text { (12.7 months f-up) } \\
\text { Better outcomes if size }<5.4 \mathrm{~cm}^{2} \\
\text { and/or BMl }<27.5\end{array}$ \\
\hline $\begin{array}{l}\text { Koh [74] } 2014 \\
\text { Arthroscopy }\end{array}$ & RCT & IA injection & $\begin{array}{l}\text { Subcutaneous fat } \\
\text { HTO + PRP vs. HTO + } \\
\text { PRP + SVF }\end{array}$ & Knee OA & $\begin{array}{l}23 \mathrm{HTO}+\mathrm{PRP}+\mathrm{SVF} \\
21 \mathrm{HTO}+\mathrm{PRP}\end{array}$ & 24 months & $\begin{array}{l}\text { SVF produced better } \\
\text { improvement of KOOS pain and } \\
\text { symptoms and VAS pain } \\
\text { Fibrocartilage coverage SVF } 50 \text { vs. } \\
10 \% \text { control }\end{array}$ \\
\hline $\begin{array}{l}\text { Pak [61] } 2013 \\
\text { BMC Musculoskelet } \\
\text { Disord }\end{array}$ & Case series & IA injection & $\begin{array}{l}\text { Subcutaneous fat SVF } \\
+ \text { PRP }\end{array}$ & OA (various joints) & 91 & 26.7 months & $\begin{array}{l}\text { SVF/PRP injections are safe } \\
\text { Clinical improvement knee and } \\
\text { hip }\end{array}$ \\
\hline $\begin{array}{l}\text { Kim [68] } 2013 \\
\text { AJSM }\end{array}$ & Comparative & IA injection & $\begin{array}{l}\text { Subcutaneous fat SVF } \\
+ \text { PRP }\end{array}$ & $\begin{array}{l}\text { Isolated defect in } \\
\text { ankle OA }\end{array}$ & $\begin{array}{l}35 \mathrm{MFX} \\
30 \mathrm{MFX}+\mathrm{SVF}\end{array}$ & 21.8 months & $\begin{array}{l}\text { Clinical improvement both groups } \\
\text { SVF group better results, especially } \\
\text { applied to Tegner score } \\
\text { Large lesion and/or subchondral } \\
\text { cysts affected outcomes only for } \\
\text { MFX alone }\end{array}$ \\
\hline $\begin{array}{l}\text { Koh [65] } 2013 \\
\text { KSSTA }\end{array}$ & Case series & IA injection & $\begin{array}{l}\text { Subcutaneous fat } \\
\text { SVF + PRP }\end{array}$ & Knee OA & 30 & 24 months & $\begin{array}{l}\text { Significant clinical improvement } \\
14 / 16(87.5 \%) \text { of } 2 \text { nd look } \\
\text { arthroscopy within } 24 \text { months } \\
\text { improved or maintained cartilage } \\
\text { status. } \\
\text { Further clinical improvement } 24 \\
\text { vs. } 12 \text { months }\end{array}$ \\
\hline $\begin{array}{l}\text { Koh [64] } 2013 \\
\text { Arthroscopy }\end{array}$ & Case series & $\begin{array}{l}\text { IA injection } \\
\text { after } \\
\text { debridement }\end{array}$ & $\begin{array}{l}\text { Fat pad } \\
\text { SVF + PRP }\end{array}$ & Knee OA & 18 & 24 months & $\begin{array}{l}\text { function and pain improvement. } \\
\text { Womac and MRI correlate with } \\
\text { cell no. } \\
\text { Better if OA } \leq 3\end{array}$ \\
\hline $\begin{array}{l}\text { Koh [63] } 2012 \\
\text { Knee }\end{array}$ & Comparative & $\begin{array}{l}\text { IA injection } \\
\text { After } \\
\text { debridement }\end{array}$ & $\begin{array}{l}\text { Fat pad } \\
\text { SVF + PRP }\end{array}$ & Knee OA & $\begin{array}{l}25 \text { debridement } \\
+ \text { SVF-PRP } \\
25 \text { debridement }\end{array}$ & $\begin{array}{l}12 \text { months } \\
\text { min }\end{array}$ & $\begin{array}{l}\text { Both improved scores. } \\
\text { SVF performed better in } \\
<55 \text { years and OA } \leq 3 \text { (ICRS) }\end{array}$ \\
\hline $\begin{array}{l}\text { Pak [60] } 2011 \\
\text { J Med Case Rep }\end{array}$ & Case report & IA injection & $\begin{array}{l}\text { Subcutaneous fat } \\
\text { SVF + PRP + low dose } \\
\text { dexamethasone }\end{array}$ & Knee OA & 2 & 3 months & $\begin{array}{l}\text { Clinical improvement } \\
\text { Significant positive changes at } \\
\text { MRI }\end{array}$ \\
\hline
\end{tabular}


increase at 24 months. Finally, Vega et al. [26] randomized two treatment groups for knee OA: a significantly greater improvement was shown after a single allogeneic BMSCs injection compared to control HA.

\section{Cultured BMSCs: surgical delivery}

Adachi et al. [27] observed cartilage and bone regeneration in a biopsy after cultured BMSCs implantation on hydroxyapatite-ceramic scaffold for osteochondral knee lesion (OLK). Haalem et al. [28] implanted BMSCs on a platelet fibrin glue (FG) scaffold, showing significant improvement and complete MRI filling of the cartilage defect. Kasemkijwattana et al. [29] seeded cells on a collagen scaffold with positive results in two traumatic knee lesions. Similarly, Kuroda et al. [30] had good results implanting BMSCs on collagen membrane with periosteum coverage in a judo-player knee, with hyalinelike tissue at a 12-month histology evaluation. Wakitani et al. used the same technique with positive findings also for patellofemoral lesions [31], stable at mid-term follow-up [32]. They also performed a comparative evaluation of this technique for focal defects in OA knees: two groups were treated with HTO, with or without BMSCs augmentation [33]. BMSCs-group showed better histology, but clinical scores comparable to the cell-free group. Nejadnik et al. compared BMSCs implantation with first-generation ACI in two groups of patients and observed comparable benefits [34].

Finally, Richter et al. [35] investigated the outcomes offered by BMSCs onto a collagen matrix for chondral ankle lesions, confirming no complications and a promising clinical improvement at 24 months of follow-up.

\section{BMC: injective treatment}

A single study by Varma et al. [36] reported promising results with $\mathrm{BMC}$ injection after arthroscopic debridement for knee OA, with increased benefits compared to debridement alone.

\section{BMC: surgical delivery}

The group of Giannini published several studies of scaffold-associated BMC implantation in knee and ankle joint defects. In their first study [37], they showed clinical and MRI improvements at 24 months after BMC implantation into collagen powder or HA matrix for osteochondral lesions of the talus (OLTs). Later [38], they reported a significant worsening between 24 and 48 months of follow-up, but the final result was still satisfactory compared to the basal level. Patients with longer symptoms before surgery had worse clinical outcomes. They also observed no degeneration progression at 24 months in five hemophilic ankle lesions [39], and similar results were confirmed in a larger group of patients treated for OLTs or ankle OA defects [40]. Also, this study showed a worsening trend after 24 months with a higher failure rate, which underlined the influence of OA degree and patient BMI. Moreover, a further study by Buda et al. [41] confirmed a similar trend of gradual worsening up to 72 months after scaffoldassisted BMC implantation.

Giannini et al. [42] also performed comparative evaluations: positive and similar clinical outcomes were found in three groups of patients treated with one-step BMCHA matrix implantation versus open ACI or arthroscopic MACT for OLTs at 36 months of follow-up. These results were later confirmed at 48 months after collagen scaffold implantation, seeded either with BMC or cultured chondrocytes, with better tissue quality at MRI for the BMC group [43]. Moreover, a RCT by Cadossi et al. [44] highlighted that biophysical stimulation with pulsed electromagnetic fields (PEMFs) might improve the results at 12 months after collagen matrixBMC implantation for OLTs.

Matrix-assisted BMC implantation was also investigated for the treatment of OLKs. The promising results using BMC on HA matrix were first reported by Buda et al. at short-term follow-up, with positive MRI and histology findings $[45,46]$, and then confirmed by Gobbi et al. [47], who observed superior outcomes using BMC instead of chondrocytes for the treatment of large patellofemoral defects. Similar results were obtained also by seeding BMC on collagen scaffolds: Gigante et al. [48] used BMC-enhanced AMIC technique with positive short-term clinical results, but limited tissue quality at histology [49], and Gobbi et al. [50] observed hyaline appearance and better short-term improvement in patients younger than 45 years and with single and smaller lesion. Finally, Skowronski et al. [51] documented stable mid-term outcomes after the treatment of large chondral lesions.

\section{PBSCs}

The possibility of using autologous PBSCs obtained by culture expansion from a venous sample was first introduced by Saw et al. [52], who treated chondral knee lesions with subchondral drilling and five postoperative i.a. injections of PBSCs and HA, reporting no adverse reactions and positive histological findings. Turajane and colleagues [53] showed short-term clinical improvement using the same technique in early knee OA patients. Later, the group of Saw [54] also performed a RCT, documenting comparable clinical outcomes at 24 months, but better MRI and histological evaluations versus HA control.

With regard to surgical application, Fu et al. [55] reported optimal results at 7.5 years in a lateral trochlea lesion treated with patellar realignment plus periosteumcovered PBSCs implantation in a kick boxer, and 
Skowronski et al. [56] implanted PBSCs with a collagen membrane in a group of patients, reporting a stable improvement up to 72-month follow-up.

\section{ADSCs}

ADSCs present a lower chondrogenic potential when compared with BMSCs [57]. Nonetheless, they can be obtained from liposuction, a simple and cheap procedure, and their clinical use is rapidly increasing, thanks to their easy availability and abundance [10]. Whereas the use of cultured cells has rarely been reported, the preferred technique involves cell harvest, collagenase digestion, and isolation of the stromal vascular fraction (SVF), a heterogeneous cell population that, among preadipocytes and immune cells, also includes ADSCs [58].

\section{Injective treatment}

Jo et al. [59] published the only available study on cultured ADSCs, applied at different doses: their preliminary clinical data showed no adverse events, and a clinical-MRI improvement at 6 months after injecting the highest dose.

Most of the literature focused instead on SVF. Regarding knee OA, Pak et al. [60] first obtained a promising clinical improvement 3 months after i.a. injection of subcutaneous SVF with HA, dexamethasone, and PRP in a patient. Later, they [61] confirmed safety and effectiveness of SVF injections in a larger cohort of patients treated into different joints. Bui et al. [62] also reported short-term clinical and MRI improvement after injection of SVF and PRP. However, the group of Koh was the main investigator of SVF use, starting from the infrapatellar fat pad source, in a case-control study [63]: all patients underwent debridement and the treatment group received an additional SVF-PRP injection. No major adverse events and a tendency for better outcomes were observed in the SVF group. The improvement was confirmed at 24 months in a further study [64]. The number of injected cells correlated with both clinical and MRI outcomes, while SVF had lower effects on the final stage OA. Later, the same group began to process subcutaneous fat with an analogous technique. They treated knee OA in elderly patients with arthroscopic lavage and SVF-PRP injection [65]: clinical improvement was obtained both at 12 and 24 months, and positive findings were reported at second look evaluation. Moreover, SVF injections significantly improved the benefits of high tibial osteotomy (HTO) for symptomatic varus knee, compared to control (HTO and PRP-only), both at clinical and second look evaluation [66].

Michalek et al. [67] administered single-dose SVF injections to the largest available group of patients, reporting no treatment-related adverse events and gradual clinical improvement between 3 and 12 months, with a slower recovery for obese and higher OA degrees.

Finally, the group of Koh also investigated SVF use in the ankle joint: Kim et al. injected SVF after marrow stimulation in two comparative studies, and observed higher clinical and MRI improvement both for ankle OA [68] or OLTs [69], compared to surgery alone. The benefit was greater for younger patients with smaller lesions, but the treatment was effective even in older patients.

\section{Surgical delivery}

Koh et al. [70] reported a significant clinical improvement 2 years after a scaffold-free SVF implantation for focal chondral lesions in OA knees, but abnormal repair tissue was observed in most cases at second look evaluation. In a subsequent study, the association with FG as scaffold significantly improved tissue quality, even though clinical results remained similar to SVF alone [71]. Later, they reported positive short-term results and correlation with MRI findings after SVF-FG implantation for OA [72]. Furthermore, a larger prospective study confirmed good/excellent results in $75 \%$ patients at 24 months [73]. Interestingly, older age, higher BMI, and larger defect size were negative predictors in all these studies. SVF-FG augmentation also improved the outcome versus $\mathrm{MF}$ alone in an RCT, despite comparable histology findings [74].

Finally, a study on matched-paired groups found comparable clinical results but better ICRS macroscopic scores at 12 months for SVF surgical implantation versus injective delivery, whereas at the further follow-up, a significant clinical superiority was also obtained for surgical SVF delivery [75].

\section{SDSCs}

SDSCs are a promising source of stem cells for cartilage tissue engineering, thanks to the greatest chondrogenic and lowest osteogenic potential among MSCs [57]. Sekiya et al. [76] reported promising results up to midterm follow-up using SDMSCs scaffold-free implantation into single knee cartilage defects, with $3 / 4$ biopsies showing hyaline cartilage.

\section{Comparative studies}

Skowronski et al. [77] performed the only clinical comparative study among stem cell types showing superior results with PBSCs rather than BMC under a collagen membrane for OLKs at 5-year follow-up.

\section{Discussion}

This systematic research highlighted that the use of mesenchymal precursors as a biological approach to treat cartilage lesions and OA has widely increased (Fig. 2), as confirmed by the growing number of clinical trials 
published on this topic. In addition to an intensive preclinical research, the use of these procedures has recently broken down the barriers towards clinical application, with more than half of the available papers published in the last 3 years. Different sources have been investigated for clinical application, especially targeting knee or ankle cartilage disease. Among them, the most exploited cell types are those derived from bone marrow and adipose tissue. Cells have been used either after culture expansion or simply concentrated for one-step procedures: in particular, adipose cells have been applied mainly through cell concentration, and cells derived from bone marrow are currently applied both after expansion or concentration, while PBSCs and SDSCs can be only exploited through in vitro expansion due to their low number.

Regardless of cell source and manipulation, cells have being administered either surgically or through i.a. injection, to target focal lesions as well as degenerative joint disease.

Overall, despite the increasing literature on this topic, there is still limited evidence about the use of MSCs for the treatment of articular cartilage, in particular as far as high-level studies are concerned: in fact, most of the available papers are case series, while only few papers reported RCTs. Moreover, the few high level studies do not allow to clearly prove the effective potential of MSCs, due to the limited number of patients treated and to the presence of several confounding factors (PRP concomitant use, cell use in combination with scaffolds, etc.). To this regard, while several studies applied cells in association with PRP, with the rationale to provide both cells and growth factors at the same time, there is no evidence that adding platelet-derived growth factors provides any increased benefit with respect to cell administration alone, and specifically designed studies are needed in order to clarify the role of PRP with respect to MSCs and/or scaffolds in cartilage treatment. Furthermore, the tissue harvest procedure poses practical and ethical limitations which prevent from performing studies with a blinded design, therefore leaving an important bias related to the placebo effect, which is an important issue in this field of new fashionable regenerative treatments.

On the other hand, the available studies still allow to draw some indications on potential and limitations of MSCs clinical use for the treatment of cartilage lesions and OA.

First, the use of MSCs in the clinical setting can be considered safe, since no major adverse events related to the treatment nor to the cell harvest have been reported, at least from the available reports at short- to mid-term follow-up. Second, a clinical benefit of using MSCs therapies has been reported in most of the studies, regardless of cell source, indication, or administration method. This effectiveness has been reflected by clinical improvement but also positive MRI and macroscopic findings, whereas histologic features gave more controversial results among different studies. Third, different studies also gave a few indications regarding the patients who might benefit more from MSCs treatment: young age, lower BMI, smaller lesion size for focal lesions, and earlier stages of OA joints have been shown to correlate with better outcomes, even though the available data strength does not allow to define clear cutoff values.

The systematic analysis of the literature also allowed to underline other interesting findings that deserve to be discussed. Definite trends can be observed with regard to the delivery method: while different combinations of products and delivery methods have been investigated over the years, currently cultured cells are mostly being administered by i.a. injection, while one-step surgical implantation is preferred for cell concentrates. The different trends observed in this field are explained both by the controversial preclinical and clinical findings, which still leaves space for clinical investigations in opposite direction, but also by practical considerations, both in terms of economical, ethical, and regulatory limitations [6]. Many aspects are taken in consideration for the treatment choice, with physicians and researchers exploring different strategies, each one presenting potential advantages and possible drawbacks. To this regard, while culture expansion guarantees a selected MSC lineage to be delivered, but presenting high costs and some contamination risks related to cell manipulation, cell concentration offers a lower number of MSCs, in a heterogeneous cell population, and can be performed in one step, thus simplifying the procedure, reducing costs, and increasing patient compliance. To date, no clear evidence of superior outcome between the two cell manipulations is available, and also their most effective delivery method remains to be defined, with only a single retrospective study reporting better results for surgical delivery compared to i.a. SVF injection in a matchedpaired analysis of two groups treated for single focal defects in knee OA [75]. Regarding surgical implantation, the use of solid scaffolds has been shown to be beneficial for SVF implantation [71], and it is the gold standard for the application of BMC [37-41, 43, 47, 48, 50, 51]. The good results obtained with scaffolds implanted with BMC have been compared with chondrocyte-based surgical techniques, showing similar outcomes, but with the advantage of the one-step approach $[42,43,47]$.

Finally, regardless of cell source, manipulation and delivery method, the optimal cell dose is still under investigation. After a first preliminary study reported no complications related to high dose of cultured ADSCs [59], only a single clinical study specifically focused on 
this aspect, suggesting benefits and absence of side effects by using higher dose of BMSCs for the treatment of post-meniscectomized knees [25]. However, the lack of standardization and the heterogeneity of the studies reported in the current literature do not allow to extend these findings to the several proposed MSCs treatment strategies.

The clinical application of MSCs for the treatment of articular cartilage defects and OA shows promising results, but too many questions still remain open. Even though no complications have been reported, longer follow-ups on broader patient population are needed to confirm the safety of these procedures. Likewise, while promising results have been shown, the potential of these treatments should be confirmed by reliable clinical data through double-blind, controlled, prospective, and multicenter studies with longer follow-up. In addition, specific studies should be designed to identify the best cell sources, manipulation, and delivery techniques, as well as pathology and disease phase indications, with the aim of optimizing the outcome for a treatment focused on focal chondral defects or joint degeneration.

\section{Conclusions}

This systematic review revealed a high interest of researchers in the clinical use of MSCs for cartilage and OA treatment, as testified by the increasing number of reports published over time. Whereas the lack of contraindication and generally promising clinical outcomes have been reported, the prevalence of low-quality studies, with many variables, shows several aspects that still need to be optimized, such as the best cell source and the most appropriate processing method, the most effective dose and delivery procedure. On the other hand, the first hints on the kind of patients who might benefit more from these procedures are being drawn. High-level studies with large number of patients and long-term follow-up are mandatory to evaluate the real potential of this biological approach for cartilage repair.

\begin{abstract}
Abbreviations
ADSCs: mesenchymal stem cells derived from adipose tissue; BMC: bone marrow concentrate; BMSCs: bone marrow expanded stem cells; FG: fibrin glue; HA: hyaluronic acid; HTO: high tibial osteotomy; i.a.: intra-articular; MAST: matrix-assisted stem cells transplantation; MFX: microfractures; MSCs: mesenchymal stem cells; OA: osteoarthritis; OLK: osteochondral knee lesion; OLTs: osteochondral lesions of the talus; PBSCs: stem cells derived from peripheral blood; PEMFs: pulsed electromagnetic fields; RCT: randomized controlled trial; SDSCs: mesenchymal stem cells derived from synovial tissue; SVF: stromal vascular fraction.
\end{abstract}

\section{Competing interests}

The authors declare that they have no competing interests.

\section{Authors' contributions}

All authors were involved in the conception and design of the study or acquisition of data or analysis and interpretation of data and contributed to drafting the article or revising it critically for important intellectual content. All authors gave their final approval of the manuscript to be submitted.

\section{Acknowledgements}

This project received institutional support by the Italian Ministry of Health Ricerca Finalizzata (RF-2011-02352638).

\section{Author details}

${ }^{1}$ Il Orthopaedic and Traumatologic Clinic, Rizzoli Orthopaedic Institute, Bologna, Italy. ${ }^{2}$ Nanobiotechnology Laboratory, Rizzoli Orthopaedic Institute, Via di Barbiano 1/10, 40136 Bologna, Italy.

Received: 16 February 2016 Accepted: 29 March 2016

Published online: 12 April 2016

\section{References}

1. Helmick CG, Felson DT, Lawrence RC, Gabriel S, Hirsch R, Kwoh CK, Liang $\mathrm{MH}$, Kremers HM, Mayes MD, Merkel PA, et al. Estimates of the prevalence of arthritis and other rheumatic conditions in the United States. Part I. Arthritis Rheum. 2008:58:15-25.

2. Litwic A, Edwards MH, Dennison EM, Cooper C. Epidemiology and burden of osteoarthritis. Br Med Bull. 2013;105:185-99.

3. Di Martino A, Kon E, Perdisa F, Sessa A, Filardo G, Neri MP, Bragonzoni L, Marcacci M. Surgical treatment of early knee osteoarthritis with a cell-free osteochondral scaffold: results at 24 months of follow-up. Injury. 2015;46 Suppl 8:S33-8.

4. Kon E, Filardo G, Drobnic M, Madry H, Jelic M, van Dijk N, Della Villa S. Nonsurgical management of early knee osteoarthritis. Knee Surg Sports Traumatol Arthrosc. 2012:20:436-49.

5. Kon E, Filardo G, Roffi A, Andriolo L, Marcacci M. New trends for knee cartilage regeneration: from cell-free scaffolds to mesenchymal stem cells. Curr Rev Musculoskelet Med. 2012;5:236-43.

6. Filardo G, Madry H, Jelic M, Roffi A, Cucchiarini M, Kon E. Mesenchymal stem cells for the treatment of cartilage lesions: from preclinical findings to clinical application in orthopaedics. Knee Surg Sports Traumatol Arthrosc. 2013;21:1717-29.

7. Manferdini C, Maumus M, Gabusi E, Piacentini A, Filardo G, Peyrafitte JA, Jorgensen C, Bourin P, Fleury-Cappellesso S, Facchini A, et al. Adiposederived mesenchymal stem cells exert antiinflammatory effects on chondrocytes and synoviocytes from osteoarthritis patients through prostaglandin E2. Arthritis Rheum. 2013;65:1271-81.

8. Caplan Al. All MSCs are pericytes? Cell Stem Cell. 2008;3:229-30.

9. Caplan Al. New era of cell-based orthopedic therapies. Tissue Eng Part B Rev. 2009;15:195-200.

10. Perdisa F, Gostynska N, Roffi A, Filardo G, Marcacci M, Kon E. Adiposederived mesenchymal stem cells for the treatment of articular cartilage: a systematic review on preclinical and clinical evidence. Stem Cells Int. 2015;2015:597652

11. Ahmed TA, Hincke MT. Mesenchymal stem cell-based tissue engineering strategies for repair of articular cartilage. Histol Histopathol. 2014;29:669-89.

12. Berg L, Koch T, Heerkens T, Bessonov K, Thomsen P, Betts D. Chondrogenic potential of mesenchymal stromal cells derived from equine bone marrow and umbilical cord blood. Vet Comp Orthop Traumatol. 2009;22:363-70.

13. Kotobuki N, Hirose M, Takakura Y, Ohgushi H. Cultured autologous human cells for hard tissue regeneration: preparation and characterization of mesenchymal stem cells from bone marrow. Artif Organs. 2004;28:33-9.

14. Sensebe L, Krampera M, Schrezenmeier H, Bourin P, Giordano R. Mesenchymal stem cells for clinical application. Vox Sang. 2010;98:93-107.

15. Indrawattana N, Chen G, Tadokoro M, Shann LH, Ohgushi H, Tateishi T, Tanaka J, Bunyaratvej A. Growth factor combination for chondrogenic induction from human mesenchymal stem cell. Biochem Biophys Res Commun. 2004:320:914-9.

16. Centeno CJ, Busse D, Kisiday J, Keohan C, Freeman M, Karli D. Increased knee cartilage volume in degenerative joint disease using percutaneously implanted, autologous mesenchymal stem cells. Pain Physician. 2008;11:343-53.

17. Davatchi F, Abdollahi BS, Mohyeddin M, Shahram F, Nikbin B. Mesenchymal stem cell therapy for knee osteoarthritis. Preliminary report of four patients. Int J Rheum Dis. 2011;14:211-5.

18. Emadedin M, Aghdami N, Taghiyar L, Fazeli R, Moghadasali R, Jahangir S, Farjad R, Baghaban Eslaminejad M. Intra-articular injection of autologous mesenchymal stem cells in six patients with knee osteoarthritis. Arch Iran Med. 2012;15:422-8.

19. Rich S, Munar A, Soler Romagosa F, Peirau X, Huquet M, Alberca M, Sánchez A, García Sancho J, Orozco L. Treatment of knee osteoarthritis with 
autologous expanded bone marrow mesenchymal stem cells: 50 cases clinical and MRI results at one year follow-up. J Stem Cell Res Ther. 2015:5:7.

20. Orozco L, Munar A, Soler R, Alberca M, Soler F, Huguet M, Sentis J, Sanchez A, Garcia-Sancho J. Treatment of knee osteoarthritis with autologous mesenchymal stem cells: a pilot study. Transplantation. 2013;95:1535-41.

21. Orozco L, Munar A, Soler R, Alberca M, Soler F, Huquet M, Sentis J, Sanchez A, Garcia-Sancho J. Treatment of knee osteoarthritis with autologous mesenchymal stem cells: two-year follow-up results. Transplantation. 2014; 97:e66-8.

22. Davatchi F, Sadeghi Abdollahi B, Mohyeddin M, Nikbin B. Mesenchymal stem cell therapy for knee osteoarthritis: 5 years follow-up of three patients. Int J Rheum Dis. 2015

23. Lee KB, Wang VT, Chan YH, Hui JH. A novel, minimally-invasive technique of cartilage repair in the human knee using arthroscopic microfracture and injections of mesenchymal stem cells and hyaluronic acid-a prospective comparative study on safety and short-term efficacy. Ann Acad Med Singapore. 2012;41:511-7.

24. Wong KL, Lee KB, Tai BC, Law P, Lee EH, Hui JH. Injectable cultured bone marrow-derived mesenchymal stem cells in varus knees with cartilage defects undergoing high tibial osteotomy: a prospective, randomized controlled clinical trial with 2 years' follow-up. Arthroscopy. 2013;29:2020-8.

25. Vangsness Jr CT, Farr 2nd J, Boyd J, Dellaero DT, Mills CR, LeRoux-Williams M. Adult human mesenchymal stem cells delivered via intra-articular injection to the knee following partial medial meniscectomy: a randomized, double-blind, controlled study. J Bone Joint Surg Am. 2014;96:90-8.

26. Vega A, Martin-Ferrero MA, Del Canto F, Alberca M, Garcia V, Munar A, Orozco L, Soler R, Fuertes JJ, Huguet M, et al. Treatment of knee osteoarthritis with allogeneic bone marrow mesenchymal stem cells: a randomized controlled trial. Transplantation. 2015;99:1681-90.

27. Adachi N, Ochi M, Deie M, Ito Y. Transplant of mesenchymal stem cells and hydroxyapatite ceramics to treat severe osteochondral damage after septic arthritis of the knee. J Rheumatol. 2005;32:1615-8.

28. Haleem AM, Singergy AA, Sabry D, Atta HM, Rashed LA, Chu CR, El Shewy MT, Azzam A, Abdel Aziz MT. The clinical use of human culture-expanded autologous bone marrow mesenchymal stem cells transplanted on plateletrich fibrin glue in the treatment of articular cartilage defects: a pilot study and preliminary results. Cartilage. 2010;1:253-61.

29. Kasemkijwattana C, Hongeng S, Kesprayura S, Rungsinaporn V, Chaipinyo K, Chansiri K. Autologous bone marrow mesenchymal stem cells implantation for cartilage defects: two cases report. J Med Assoc Thai. 2011;94:395-400.

30. Kuroda R, Ishida K, Matsumoto T, Akisue T, Fujioka H, Mizuno K, Ohgushi H, Wakitani S, Kurosaka M. Treatment of a full-thickness articular cartilage defect in the femoral condyle of an athlete with autologous bone-marrow stromal cells. Osteoarthritis Cartilage. 2007;15:226-31.

31. Wakitani S, Nawata M, Tensho K, Okabe T, Machida H, Ohgushi H. Repair of articular cartilage defects in the patello-femoral joint with autologous bone marrow mesenchymal cell transplantation: three case reports involving nine defects in five knees. J Tissue Eng Regen Med. 2007;1:74-9.

32. Wakitani S, Mitsuoka T, Nakamura N, Toritsuka Y, Nakamura Y, Horibe S. Autologous bone marrow stromal cell transplantation for repair of fullthickness articular cartilage defects in human patellae: two case reports. Cell Transplant. 2004;13:595-600.

33. Wakitani S, Imoto K, Yamamoto T, Saito M, Murata N, Yoneda M. Human autologous culture expanded bone marrow mesenchymal cell transplantation for repair of cartilage defects in osteoarthritic knees. Osteoarthritis Cartilage. 2002;10:199-206

34. Nejadnik H, Hui JH, Feng Choong EP, Tai BC, Lee EH. Autologous bone marrow-derived mesenchymal stem cells versus autologous chondrocyte implantation: an observational cohort study. Am J Sports Med. 2010:38:1110-6.

35. Richter M, Zech S. Matrix-associated stem cell transplantation (MAST) in chondral defects of foot and ankle is effective. Foot Ankle Surg. 2013;19:84-90.

36. Varma HS, Dadarya B, Vidyarthi A. The new avenues in the management of osteo-arthritis of knee-stem cells. J Indian Med Assoc. 2010;108:583-5.

37. Giannini S, Buda R, Vannini F, Cavallo M, Grigolo B. One-step bone marrowderived cell transplantation in talar osteochondral lesions. Clin Orthop Relat Res. 2009;467:3307-20.

38. Giannini S, Buda R, Battaglia M, Cavallo M, Ruffilli A, Ramponi L, Pagliazzi G, Vannini F. One-step repair in talar osteochondral lesions: 4-year clinical results and t2-mapping capability in outcome prediction. Am J Sports Med. 2013;41:511-8
39. Buda R, Cavallo M, Castagnini F, Cenacchi A, Natali S, Vannini F, Giannini S Treatment of hemophilic ankle arthropathy with one-step arthroscopic bone marrow-derived cells transplantation. Cartilage. 2015;6:150-5.

40. Buda R, Castagnini F, Cavallo M, Ramponi L, Vannini F, Giannini S. "Onestep" bone marrow-derived cells transplantation and joint debridement for osteochondral lesions of the talus in ankle osteoarthritis: clinical and radiological outcomes at 36 months. Arch Orthop Trauma Surg. 2015.

41. Buda R, Vannini F, Cavallo M, Baldassarri M, Natali S, Castagnini F, Giannini S. One-step bone marrow-derived cell transplantation in talarosteochondral lesions: mid-term results. Joints. 2013;1:102-7.

42. Giannini S, Buda R, Cavallo M, Ruffilli A, Cenacchi A, Cavallo C, Vannini F. Cartilage repair evolution in post-traumatic osteochondral lesions of the talus: from open field autologous chondrocyte to bone-marrow-derived cells transplantation. Injury. 2010;41:1196-203.

43. Buda R, Vannini F, Castagnini F, Cavallo M, Ruffilli A, Ramponi L, Pagliazzi G, Giannini S. Regenerative treatment in osteochondral lesions of the talus: autologous chondrocyte implantation versus one-step bone marrow derived cells transplantation. Int Orthop. 2015;39:893-900.

44. Cadossi M, Buda RE, Ramponi L, Sambri A, Natali S, Giannini S. Bone marrow-derived cells and biophysical stimulation for talar osteochondral lesions: a randomized controlled study. Foot Ankle Int. 2014;35:981-7.

45. Buda R, Vannini F, Cavallo M, Grigolo B, Cenacchi A, Giannini S. Osteochondral lesions of the knee: a new one-step repair technique with bone-marrow-derived cells. J Bone Joint Surg Am. 2010;92 Suppl 2:2-11.

46. Buda R, Vannini F, Cavallo M, Baldassarri M, Luciani D, Mazzotti A, Pungetti C, Olivieri A, Giannini S. One-step arthroscopic technique for the treatment of osteochondral lesions of the knee with bone-marrow-derived cells: three years results. Musculoskelet Surg. 2013;97:145-51.

47. Gobbi A, Chaurasia S, Karnatzikos G, Nakamura N. Matrix-induced autologous chondrocyte implantation versus multipotent stem cells for the treatment of large patellofemoral chondral lesions: a nonrandomized prospective trial. Cartilage. 2015;6:82-97.

48. Gigante A, Cecconi S, Calcagno S, Busilacchi A, Enea D. Arthroscopic knee cartilage repair with covered microfracture and bone marrow concentrate. Arthrosc Tech. 2012;1:e175-80.

49. Gigante A, Calcagno S, Cecconi S, Ramazzotti D, Manzotti S, Enea D. Use of collagen scaffold and autologous bone marrow concentrate as a one-step cartilage repair in the knee: histological results of second-look biopsies at 1 year follow-up. Int J Immunopathol Pharmacol. 2011;24:69-72.

50. Gobbi A, Karnatzikos G, Sankineani SR. One-step surgery with multipotent stem cells for the treatment of large full-thickness chondral defects of the knee. Am J Sports Med. 2014;42:648-57.

51. Skowronski J, Skowronski R, Rutka M. Large cartilage lesions of the knee treated with bone marrow concentrate and collagen membrane-results. Ortop Traumatol Rehabil. 2013;15:69-76.

52. Saw KY, Anz A, Merican S, Tay YG, Ragavanaidu K, Jee CS, McGuire DA. Articular cartilage regeneration with autologous peripheral blood progenitor cells and hyaluronic acid after arthroscopic subchondral drilling: a report of 5 cases with histology. Arthroscopy. 2011;27:493-506.

53. Turajane T, Chaweewannakorn U, Larbpaiboonpong V, Aojanepong J, Thitiset T, Honsawek S, Fongsarun J, Papadopoulos Kl. Combination of intraarticular autologous activated peripheral blood stem cells with growth factor addition/ preservation and hyaluronic acid in conjunction with arthroscopic microdrilling mesenchymal cell stimulation Improves quality of life and regenerates articular cartilage in early osteoarthritic knee disease. J Med Assoc Thai. 2013;96:580-8.

54. Saw KY, Anz A, Siew-Yoke Jee C, Merican S, Ching-Soong Ng R, Roohi SA, Ragavanaidu K. Articular cartilage regeneration with autologous peripheral blood stem cells versus hyaluronic acid: a randomized controlled trial. Arthroscopy. 2013;29:684-94.

55. Fu WL, Ao YF, Ke XY, Zheng ZZ, Gong X, Jiang D, Yu JK. Repair of large fullthickness cartilage defect by activating endogenous peripheral blood stem cells and autologous periosteum flap transplantation combined with patellofemoral realignment. Knee. 2014;21:609-12.

56. Skowronski J, Skowronski R, Rutka M. Cartilage lesions of the knee treated with blood mesenchymal stem cells-results. Ortop Traumatol Rehabil. 2012;14:569-77.

57. Koga H, Muneta $T$, Nagase $T$, Nimura A, Ju YJ, Mochizuki T, Sekiya I. Comparison of mesenchymal tissues-derived stem cells for in vivo chondrogenesis: suitable conditions for cell therapy of cartilage defects in rabbit. Cell Tissue Res. 2008;333:207-15. 
58. Jang Y, Koh YG, Choi YJ, Kim SH, Yoon DS, Lee M, Lee JW. Characterization of adipose tissue-derived stromal vascular fraction for clinical application to cartilage regeneration. In Vitro Cell Dev Biol Anim. 2015:51:142-50.

59. Jo CH, Lee YG, Shin WH, Kim H, Chai JW, Jeong EC, Kim JE, Shim H, Shin JS, Shin IS, et al. Intra-articular injection of mesenchymal stem cells for the treatment of osteoarthritis of the knee: a proof-of-concept clinical trial. Stem Cells. 2014;32:1254-66.

60. Pak J. Regeneration of human bones in hip osteonecrosis and human cartilage in knee osteoarthritis with autologous adipose-tissue-derived stem cells: a case series. J Med Case Rep. 2011:5:296

61. Pak J, Chang JJ, Lee JH, Lee SH. Safety reporting on implantation of autologous adipose tissue-derived stem cells with platelet-rich plasma into human articular joints. BMC Musculoskelet Disord. 2013;14:337.

62. Bui K, Duong $T$, Nguyen N, Nguyen $T$, Le $\mathrm{V}$, Thanh Mai V, Lu-Chinh Phan N, Le Minh D, Ngoc N, Van Pham P. Symptomatic knee osteoarthritis treatment using autologous adipose derived stem cells and platelet-rich plasma: a clinical study. Biomedical Research and Therapy. 2014;1:02-8.

63. Koh YG, Choi YJ. Infrapatellar fat pad-derived mesenchymal stem cell therapy for knee osteoarthritis. Knee. 2012;19:902-7.

64. Koh YG, Jo SB, Kwon OR, Suh DS, Lee SW, Park SH, Choi YJ. Mesenchymal stem cell injections improve symptoms of knee osteoarthritis. Arthroscopy. 2013;29:748-55.

65. Koh YG, Choi YJ, Kwon SK, Kim YS, Yeo JE. Clinical results and second-look arthroscopic findings after treatment with adipose-derived stem cells for knee osteoarthritis. Knee Surg Sports Traumatol Arthrosc. 2015;23:1308-16.

66. Koh YG, Kwon OR, Kim YS, Choi YJ. Comparative outcomes of open-wedge high tibial osteotomy with platelet-rich plasma alone or in combination with mesenchymal stem cell treatment: a prospective study. Arthroscopy. 2014;30:1453-60

67. Michalek J, Moster R, Lukac L, Proefrock K, Petrasovic M, Rybar J, et al. Autologous adipose tissue-derived stromal vascular fraction cells application in patients with osteoarthritis. Cell Transplant. 2015.

68. Kim YS, Park EH, Kim YC, Koh YG. Clinical outcomes of mesenchymal stem cell injection with arthroscopic treatment in older patients with osteochondral lesions of the talus. Am J Sports Med. 2013:41:1090-9.

69. Kim YS, Lee HJ, Choi YJ, Kim YI, Koh YG. Does an injection of a stromal vascular fraction containing adipose-derived mesenchymal stem cells influence the outcomes of marrow stimulation in osteochondral lesions of the talus? A clinical and magnetic resonance imaging study. Am J Sports Med. 2014:42:2424-34.

70. Koh YG, Choi YJ, Kwon OR, Kim YS. Second-look arthroscopic evaluation of cartilage lesions after mesenchymal stem cell implantation in osteoarthritic knees. Am J Sports Med. 2014;42:1628-37.

71. Kim YS, Choi YJ, Suh DS, Heo DB, Kim YI, Ryu JS, Koh YG. Mesenchymal stem cell implantation in osteoarthritic knees: is fibrin glue effective as a scaffold? Am J Sports Med. 2015;43:176-85.

72. Kim YS, Choi YJ, Lee SW, Kwon OR, Suh DS, Heo DB, Koh YG. Assessment of clinical and MRI outcomes after mesenchymal stem cell implantation in patients with knee osteoarthritis: a prospective study. Osteoarthritis Cartilage. 2016;24:237-45.

73. Kim YS, Choi YJ, Koh YG. Mesenchymal stem cell implantation in knee osteoarthritis: an assessment of the factors influencing clinical outcomes. Am J Sports Med. 2015;43:2293-301.

74. Koh YG, Kwon OR, Kim YS, Choi YJ, Tak DH. Adipose-derived mesenchymal stem cells with microfracture versus microfracture alone: 2-year follow-up of a prospective randomized trial. Arthroscopy. 2016;32:97-109.

75. Kim YS, Kwon OR, Choi YJ, Suh DS, Heo DB, Koh YG. Comparative matchedpair analysis of the injection versus implantation of mesenchymal stem cells for knee osteoarthritis. Am J Sports Med. 2015:43:2738-46.

76. Sekiya I, Muneta T, Horie M, Koga H. Arthroscopic transplantation of synovial stem cells improves clinical outcomes in knees with cartilage defects. Clin Orthop Relat Res. 2015;473:2316-26.

77. Skowronski J, Rutka M. Osteochondral lesions of the knee reconstructed with mesenchymal stem cells—results. Ortop Traumatol Rehabil. 2013;15:195-204.

\section{Submit your next manuscript to BioMed Central and we will help you at every step:}

- We accept pre-submission inquiries

- Our selector tool helps you to find the most relevant journal

- We provide round the clock customer support

- Convenient online submission

- Thorough peer review

- Inclusion in PubMed and all major indexing services

- Maximum visibility for your research

Submit your manuscript at www.biomedcentral.com/submit

) Biomed Central 